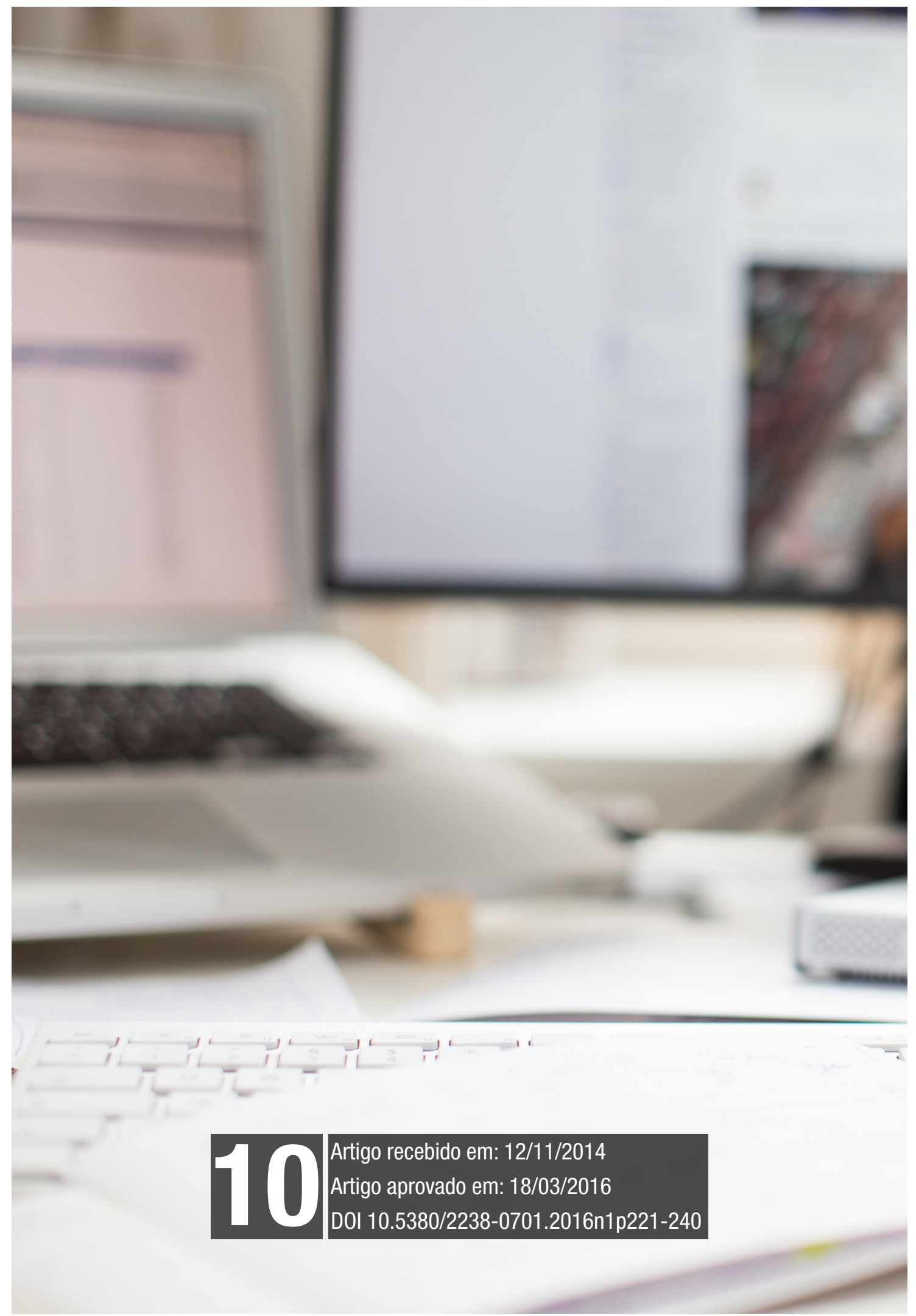


Curadoria. Breaking News. Jornalista.

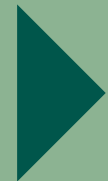




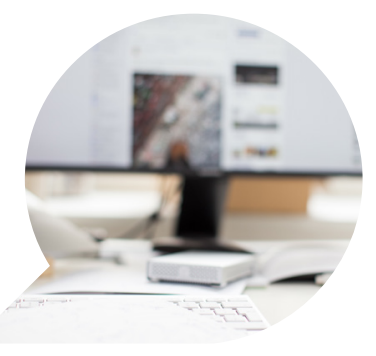

\section{A curadoria em jornalismo nas coberturas de breaking news em tempo real na internet}

Journalism curation on breaking news coverage in real time on the internet

Curaduría periodistica en las coberturas de breaking news en tiempo real en la internet

\section{MORENO CRUZ OSÓRIO *}

Resumo: Este artigo propõe uma discussão sobre a curadoria de conteúdo como forma de verificação jornalística e como parte do processo de construção da notícia durante coberturas de caráter urgente que têm a internet como suporte de publicação, a partir das possibilidades proporcionadas pelas tecnologias ao profissional longe do local do fato, utilizando informações que circulam na rede para gerar conhecimento.

Palavras-chave: Curadoria; Breaking news; Jornalista.

Abstract: This paper proposes a discussion about content curation as a form of journalistic verification and as part of the news

* Jornalista, doutorando em Comunicação na Unisinos. O presente trabalho foi realizado com apoio do CNPq, Conselho Nacional de Desenvolvimento Científico e Tecnológico - Brasil. 
construction during crisis coverage content on the internet The proposition is based on the power provided by technology to the professional working away from the place where the fact is happening, using information available on the web to generate knowledge.

Keywords: Curation; Breaking news; Journalist.

Resumen: En este trabajo se propone un debate sobre la curaduría de contenidos como una forma de verificación periodística y como parte de la construcción de las noticias durante la cobertura de carácter urgente que tiene el Internet para apoyar el proceso de publicación, a partir de las posibilidades que ofrece la tecnología para trabajar lejos del sitio de hecho, utilizando la información que circula en la red para generar conocimiento.

Palabras clave: Curaduría; Breaking news; Periodismo. 


\section{Introdução: jornalista gatewatcher em um ambiente de breaking news}

Assumir a ideia de jornalista digital como um "observador dos portões", ou gatewatcher, expressão cunhada por Bruns (2005), em uma adaptação da definição de gatekeeper, de David Maning White, pressupõe a construção do que entendemos por notícia por meio da observação dos fluxos de informação que circulam pela internet. Em um ambiente em que o jornalista e o seu público potencialmente possuem a matéria-prima da notícia no mesmo momento, a exclusividade que o jornalismo sempre teve a uma parte importante da dinâmica que o fez ser o que ele é deixa de existir, expondo seus mecanismos a críticas e abrindo possibilidades alternativas à sua lógica. Com parte do seu "segredo" revelado, o jornalismo é desafiado a afirmar sua importância respondendo a perguntas nunca enfrentadas com facilidade. Elas giram em torno da definição de notícia e o que faz dos jornalistas os únicos capacitados a saber o que de fato ela é e, assim, produzi-las.

Se trabalharmos com a ideia de que este é o contexto geral do jornalismo atualmente, há um momento em que ele se mostra mais incisivo. É quando surge um fato capaz de quebrar uma rotina estabelecida de notícias, diferenciando-se deste fluxo e, por isso, canalizando atenções; um fato capaz de gerar um interesse maior do que o normal, seja pelo seu caráter extraordinário, catastrófico ou imponderável, seja porque vai afetar a vida de muitas pessoas. Trata-se do chamado breaking news ${ }^{1}$.

\footnotetext{
${ }^{1}$ Optamos por utilizar o termo em inglês por considerar, neste momento, que ele é mais adequado do que uma adaptação para o português. Em uma tradução literal, teríamos algo como "quebra do noticiário". Mas como o verbo quebrar não faz parte do vocabulário jornalístico, a expressão não funciona da mesma forma. Ao adaptarmos para o português, poderíamos optar por "notícia urgente", ou "plantão", se quisermos remeter ao clássico plantão de notícias da TV Globo e seu tradicional jingle. No entanto, percebemos a importância de, em outra oportunidade, tensionar este termo, seja para buscar uma justificativa mais fundamentada para o uso em inglês, seja para substituí-lo por um termo em português à altura. Por outro lado, há um tensionamento que transcende a justificativa por este ou aquele termo. Ele passa por explorar a natureza do evento breaking news. Neste momento, vislumbramos duas possibilidades não necessariamente excludentes. A primeira diz respeito aos estudos sobre o acontecimento, de maneira geral, e do acontecimento jornalístico, em particular (BENETTI e FONSECA, 2010; LEAL, ANTUNES e VAZ, 2011; QUERÉ, 2005, entre outros). A segunda discute o breaking news pelo seu viés psicológico. Fatos trágicos, imponderáveis ou mesmo improváveis geram
} 
Traquina, ao falar das práticas que definem a "tribo jornalística" (TRAQUINA, 2005), sublinha a importância do imediatismo, classificando-o como o "eixo central do campo jornalístico" (TRAQUINA, 2005, p. 38). O fetiche pelo tempo ajuda a entender o efeito de um breaking news na rotina jornalística. É o momento máximo para o jornalista mostrar sua capacidade de agir sobre o relógio, construindo uma narrativa para o seu público da forma mais rápida e objetiva possível, utilizando técnicas de seleção que possui para diferenciar o que é notícia do que não é, o que é importante do que não é, e, fundamentalmente, o que é verdade do que não é. "Os jornalistas têm uma interpretação cultural específica do verdadeiro significado do seu trabalho, na base do qual estão a excitação e o perigo que advêm do fato de depararem com apertadas horas de fechamento" (SCHLESINGER apud TRAQUINA, 2005, p. 40). A pressão faz do jornalismo uma profissão nada confortável, mas emocionante.

Mas quando Traquina discute a questão do imediatismo, a abordagem é feita a partir de uma rotina baseada em marcos temporais típicos do jornal diário impresso, cuja pressão do fechamento vinha da necessidade de enviar o jornal às rotativas, e em um contexto no qual o jornalista detinha a exclusividade da informação até que ela se transformasse em notícia, para só então chegar ao público. Este contexto mudou. Se antes o jornalista era um gatekeeper pressionado pelo fechamento do jornal para escolher o que seria notícia, hoje é um gatewatcher cujo trabalho é pinçar do caos informacional o que é notícia, processo observado por um público que o critica e - como sublinhamos - às vezes até oferece alternativas ao seu trabalho. Uma atividade talvez ainda mais emocionante, mas certamente mais desconfortável.

Este artigo se propõe a pensar o jornalismo no ambiente descrito acima, bem como o jornalista que nele atua. Propõe, portanto, uma discussão sobre as transformações pelas quais passa a construção da notícia por meio do conceito de curadoria em jornalismo, nos casos de coberturas em tempo real que utilizam a internet como suporte de publicação, e em situações em que não é possível checar informações in loco, como, em geral, é o caso do noticiário internacional, principalmente o de caráter urgente, o breaking news. Busca-se refletir de que forma é possível desenvolver e cristalizar a atividade jornalística

tensão, medo, ansiedade, fatores propícios para que rumores se espalhem, prejudicando o trabalho do jornalismo e as sociedades de maneira geral. 
a partir de uma constatação do relatório "Jornalismo Pós-Industrial - adaptação aos novos tempos”, publicado em 2012 pela Escola de Jornalismo de Columbia, a de que "o jornalista não foi substituído - foi deslocado para um ponto mais acima da cadeia editorial"2 (ANDERSON, BELL e SHIRKY, 2012, p. 43). Estar mais acima na cadeia editorial significa que abaixo está o público, cada vez mais apto a fazer as observações iniciais (tornando-as públicas, publicando-as antes do próprio jornalista) sobre um fato potencialmente jornalístico. É conviver com a ideia de que a exclusividade sobre a matéria-prima das notícias não existe mais.

O que propomos aqui é introduzir o assunto a partir de dois eixos: apresentando exemplos de iniciativas moldadas por uma evolução natural das técnicas de apuração em ambiente virtual e fazendo uma revisão bibliográfica das produções que têm refletido sobre o tema. Esses dois eixos formam uma base para aprofundar a discussão sobre esse aspecto específico do jornalismo digital.

\section{Jornalista gatewatcher e a cobertura a partir da redação}

Um exemplo dado pelo jornalista Markham Nolan sustenta a necessidade de se pensar as coberturas de breaking news realizadas pela internet a partir da redação e dá contornos ao desafio imposto ao profissional da imprensa inserido neste cenário. Em 15 de setembro de 2012, um terremoto de 7.6 graus atingiu a Costa Rica. A alta magnitude fez com que o tremor fosse sentido em toda a região. Sessenta segundos depois, o chão balançou na capital da Nicarágua, a $150 \mathrm{~km}$ do epicentro. Mais trinta segundos depois, um morador de Manágua publicou o primeiro tweet a respeito do fenômeno, possibilitando que o mundo soubesse o que acontecia na América Central. "Sessenta segundos foi o tempo que o terremoto físico levou para viajar (150

\footnotetext{
${ }^{2}$ Uma crítica comum a esta constatação do relatório é que, de maneira geral, o jornalista nunca fez as observações iniciais. Quem sempre as fez foi o público, definido neste caso como testemunhas do fato. Tais testemunhas davam seu relato aos jornalistas, que então o disponibilizavam a um público mais amplo em forma de notícia. Atualmente, o fluxo segue sendo mais ou menos esse. A diferença é que, por estar conectado, o públicotestemunha não precisa mais do jornalista para tornar seu relato de determinado fato público e potencialmente com alcance global. A constatação do relatório obviamente não ignora o fluxo tradicional, mas ressalta esta substancial diferença. Trata-se de interpretar o que diz o texto a partir de um contexto mais amplo.
} 
$\mathrm{km}$ ). Trinta segundos depois, uma notícia sobre o terremoto já havia viajado ao redor do mundo de forma instantânea" (NOLAN, 2012).

Se hoje todo o planeta tem potencialmente a capacidade de tomar conhecimento de um fato praticamente no mesmo momento em que ele acontece, julgamos relevante que o jornalismo se adapte a este cenário para tentar preservar o papel de mediador das discussões da sociedade. Sem negar a importância da reportagem on the ground (em campo, na tradução livre), com um jornalista atuando no local onde acontecem os fatos, entendemos que parte dessa adaptação passa por repensar a atuação do profissional que permanece na redação. Hoje, a manifestação mais comum desse tipo de atuação se dá nos sites e portais de notícias. É lá que este jornalista, atuando como gatewatcher, é responsável por cobrir o breaking news em andamento.

É sabido, entretanto, que as condições de atuação dos jornalistas nunca foram das mais salubres, muito em função das características do trabalho lembradas por Traquina (2005). E com o surgimento do jornalismo na web, aumentaram as constatações de deterioração dessas condições (ADGHIRNI, 2001; LOPES, 2012; PEREIRA, 2003 e 2004) e a radicalização do tipo de produção realizada pelo chamado "jornalista sentado", ou seja, o profissional "mais orientado ao tratamento (formatação dos textos de outros jornalistas, gênero editorial ou comentário) de uma informação que não é coletada pelo próprio jornalista” (NEVEU apud PEREIRA, 2004, p. 2), figura tradicionalmente vista como precária em um meio profissional marcado pela ideia romântica do repórter que vai às ruas atrás de uma boa história.

No entanto, nos últimos anos, com a ascensão das Tecnologias de Informação e Comunicação oriundas da consolidação da Internet, talvez possamos lançar um novo olhar para a prática jornalística de hard news realizada a partir da redação. Ferramentas digitais e sites de redes sociais vêm possibilitando a abertura de uma "janela para o mundo" inexistente nas primeiras gerações de jornalistas digitais, de meados da década de 1990 até o início dos anos 2000. Esta janela, importante enfatizar, não pretende substituir o trabalho do jornalista que está na rua, mas parece potencializar a atividade do profissional gatewatcher, especialmente os responsáveis por coberturas de emergência em tempo real. Ou seja, a conversação via redes sociais, as imagens do YouTube, a mineração em banco de dados digitais, só para citar exemplos básicos, oferecem a possiblidade de que se faça 
uma cobertura jornalística, nessas condições, mais completa (no mínimo mais complexa) quando comparada às realizadas há dez anos, principalmente no jornalismo internacional, editoria tradicionalmente refém dos despachos das agências (SCHIAFFARINO, 2012).

Por isso, é no noticiário internacional que esse tipo de atuação se faz mais evidente, pois a distância é um dos fatores (dentre outros, como econômicos, temporais e relativos à segurança) determinantes para que a cobertura seja feita predominantemente de maneira remota. Durante esse processo, o jornalista será acompanhado (criticado, questionado) pelo público, que, como também já dissemos, potencialmente tem acesso quase às mesmas $^{3}$ informações, ou seja, ao fluxo de dados que transita pela rede sobre aquele breaking news. Este fluxo pode ser oriundo de outros veículos de notícias, de repórteres on the ground, de testemunhas oculares, do próprio público por meio de sites de redes sociais etc.

$\mathrm{O}$ conceito de gatewatching ajuda a entender as possibilidades e limitações desse jornalista. Como vimos, o gatewatcher, em vez de "liberar" ou "barrar" a publicação de notícias, como diz a teoria do gatekeeper, de David Maning White (1950), adota a "observação dos portões de saída de veículos de imprensa e de outras fontes de modo a identificar materiais importantes assim que eles se tornem disponíveis" (BRUNS, 2005, p. 17). Desse modo, ao tentar colocar ordem no caos informacional observando o fluxo de informações disponíveis na web, a prática do jornalista gatewatcher traz à tona o que Federico Guerrini $(2013)^{4}$ classifica como curadoria de conteúdo jornalístico ${ }^{5}$, importan-

\footnotetext{
${ }^{3}$ A situação muda um pouco de figura se o jornalista gatewatcher possuir um repórter trabalhando no local onde está acontecendo o breaking news.

${ }^{4}$ No trabalho Newsroom curators \& independent storytellers: content curation as a new form of journalism ("Curadores das redações \& narradores independentes: curadoria de conteúdo como uma nova forma de jornalismo", na tradução livre), o jornalista italiano Federico Guerrini, traça um background recente das mudanças no jornalismo ocasionadas pelo surgimento e consolidação do user generated content (conteúdo gerado por usuários), principalmente através das redes sociais, para dizer que a "curadoria hoje tem um importante papel na maneira como as notícias são criadas pelas redações (ou freelancers) e então entregues à audiência" (GUERRINI, 2013, p. 9). Em seguida, ele analisa ferramentas de curadoria de conteúdo e duas coberturas em que a técnica foi utilizada por redações como a do jornal The Guardian e por jornalistas independentes: London Riots, em 2012, e Occupy Wall Street, em 2011.

${ }^{5}$ Evidentemente temos consciência que o termo curadoria vem sendo discutido nos estudos de comunicação e que Guerrini não necessariamente foi o pioneiro no assunto dentro do jornalismo, mas consideramos o seu trabalho, publicado pelo Reuters Institute for the Study of Journalism, da Universidade de Oxford, um dos mais relevantes para
} 
do um termo típico das artes. Nela, "os jornalistas, sem deixar de lado suas habilidades tradicionais, também se tornam mais e mais 'gerenciadores' de informações" (GUERRINI, 2013, p. 10).

Convém sublinhar que o termo curadoria, ao ser aplicado ao jornalismo, não significa apenas uma seleção do que "de melhor há" sobre determinado assunto, o que poderia dar margem a uma crítica ao jornalista curador como alguém funcionando apenas como reprodutor de opiniões predominantes, a serviço do status quo, e não como alguém apto a realizar mediações entre diferentes pontos de vista do assunto a ser noticiado/curado. A referência imediata são as teorias construcionistas e etnoconstrucionistas, que chamam a atenção, na hora de construir notícias, para a influência de "processos complexos de interação social entre agentes sociais: os jornalistas e as fontes de informação; os jornalistas e a sociedade; os membros da comunidade profissional" (TRAQUINA, 2004, p. 173).

\section{Curadoria jornalística digital em um ambiente de rede}

Um caso apresentado no já citado relatório "Jornalismo Pós-industrial - adaptação aos novos tempos”, publicado em 2012 pelo Tow Center for Digital Journalism, da Columbia Journalism School, e bastante conhecido no meio jornalístico, ajuda a entender o conceito de Bruns e a curadoria de conteúdo no contexto abordado por Guerrini e discutido aqui. O estudo cita o papel de Sohaib Athar, um consultor de TI que foi um dos primeiros a tornar pública a operação que resultou na morte de Osama bin Laden, em Abbottabad, no Paquistão, em 2011. Ao informar no Twitter que estava ouvindo o que pareciam ser helicópteros voando baixo, mesmo sem saber, Athar trabalhou como jornalista. E os jornalistas profissionais, embora não tenham sido os primeiros emissores daquele fato, usaram as informações fornecidas por Athar - preciosas devido ao seu caráter inédito e urgente - para reconstruir o evento ${ }^{6}$. Deram "sentido à enxurrada de texto,

ser citado neste artigo, principalmente se levarmos a especificidade do assunto tratado tanto por Guerrini quanto por nós: curadoria em jornalismo de breaking news.

${ }^{6}$ A discussão sobre o conceito de evento pode ser interessante, principalmente em relação às diferenças de eventos jornalísticos dos eventos ordinários, como discutem Berger e Tavares (2007), e consequentemente os sentidos que cada um é capaz de produzir em um momento em que eventos considerados ordinários têm uma grande possibilidade de se tornarem públicos. 
áudio, fotos e vídeos produzida pelo público" (ANDERSON, BELL e SHIRKY, 2012, p. 43).

No exemplo de Athar, assim como no do terremoto, testemunhas presenciaram um fato e deram o seu relato. Jornalistas, então, transformaram esses testemunhos em notícias, adicionando informações contextuais. Exatamente como o jornalismo sempre fez. Há, porém, duas diferenças cruciais em relação à verificação tradicional, e elas ajudam a definir o papel do jornalista curador/gatewatcher em momentos de cobertura de eventos de breaking news.

Primeiro, esses depoimentos já eram públicos antes do repórter transformá-los em notícia. Em ambas as oportunidades, isso aconteceu devido à capacidade da internet de servir como plataforma de autopublicação e ao potencial propagador das redes sociais, no caso, o Twitter. Isso significa que quase no mesmo instante em que o morador de Manágua e o paquistanês Sohaib Athar tuitaram, qualquer pessoa no mundo era um potencial receptor daquelas informações antes que elas saíssem em qualquer veículo de imprensa.

Segundo, o caminho percorrido pelo jornalista para publicar a matéria mudou. Em vez de esperar o material chegar via boletins de agências de notícias - organizações eventualmente capazes de apurar o fato localmente - ou precisar ele mesmo ir ao local do ocorrido para obter as informações, conversando com quem presenciou o acontecido para então tornar tais testemunhos públicos, ele acessa esses depoimentos de maneira direta, ainda que virtualmente, e dá sentido a um conteúdo cru e, em tese, já disponível ao público.

Esses dois pontos podem delimitar a curadoria de conteúdo jornalístico de breaking news, evidenciando-se um processo de verificação distinto do consolidado na apuração tradicional - embora o cuidado com a precisão, diga-se, seja essencial em ambos os casos. Enquanto a apuração "clássica" pode ser definida como uma trajetória pessoal do repórter, que usa seus contatos, sua capacidade de observação, sua intuição e seu conhecimento prévio para construir de forma vertical uma narrativa inédita de determinado fato, a apuração baseada em curadoria está mais ligada à observação de uma conversação já em andamento sobre este mesmo fato e à capacidade de transitar em meio a esse diálogo, avaliando constantemente a multiplicidade de vozes disponíveis em um mosaico quase infinito de possibilidades narrativas. Essa ideia foi levantada em um artigo de 2010 intitu- 
lado The Rise of Curated Crisis Content ("O Surgimento da Curadoria de Conteúdo de Crise", na tradução livre) e assinado por Sophia B. Liu. Nele, a autora introduz o conceito de socially-distributed curation (curadoria socialmente distribuída), uma maneira de contar com o poder das redes sociais para buscar informações entre usuários mais capacitados para determinados assuntos do que o próprio jornalista (alternativa com potencial em coberturas de emergência).

Trata-se de uma postura horizontal, baseada mais no engajamento e na organização de uma discussão pública do que na revelação de opiniões particulares (ou, se pensarmos de outro modo, trata-se da potencialização do processo de busca por fontes pelo repórter). Esse comportamento vai definir as ações do jornalista na hora de transformar fatos em notícias, utilizando as credenciais profissionais que possui para legitimar socialmente tal narrativa.

Raciocínio semelhante sustenta Ansgard Heinrich no livro $\mathrm{Ne}$ twork Journalism: Journalistic Practice in Interactive Spheres (Jornalismo em Rede: Práticas Jornalísticas em Esferas Interativas, na tradução livre). Para a autora, estamos deixando para trás um sistema jornalístico linear e centralizado, típico do século XX, e desenvolvendo um modelo baseado na não-linearidade e na descentralização do processo noticioso - embora este movimento ainda seja visto com suspeita e temor de queda dos padrões jornalísticos (HEINRICH, 2011).

Inclusive, a respeito desse receio, em um artigo sobre curadoria de informação, as pesquisadoras da USP, Elizabeth Saad Corrêa e Daniela Bertocchi, destacam uma passagem do livro Too big to know (Muito grande para saber, em tradução livre) em que o autor, David Weinberger, constrói uma definição do conhecimento em rede e faz um alerta: aos usarmos as redes, só nos tornaremos mais inteligentes se formos capazes de fazer com que elas joguem a nosso favor. Do contrário, nos tornaremos mais ignorantes.

Na medida em que o conhecimento ocorre em conexão, a pessoa mais inteligente de uma sala não é aquela sentada à nossa frente, e também não é o conhecimento de todos daquela sala. A pessoa mais inteligente da sala é a própria sala: a rede que agrega pessoas e ideias e as conecta àquelas que estão do lado de fora. Isso não significa que a rede está se tornando um supercérebro. É o conhecimento que está se tornando inextricável - literalmente, algo impensável - à rede. Nossa tarefa é saber construir salas inteligentes, ou seja, como construir redes que nos tornem mais inteligentes, e se isso 
for feito de forma inadequada, a rede pode fazer de nós cada vez mais ignorantes. Conhecimento em rede é menos preciso, porém, mais humano (WEINBERGER, 2012, loc. 139-148, apud CORRÊA E BERTOCCHI, 2012, p. 26).

As pesquisadoras apontam a curadoria como possível solução para o alerta feito por Weinberger. Seria uma maneira de organizar as informações das redes, transformando-as em conhecimento. Mas elas salientam que o processo não pode ficar dependente de algoritmos - instruções básicas para resolver problemas, base da lógica computacional e muito usados em curadoria de conteúdo digital automatizada. É necessário que ele esteja sustentado pela intervenção humana (sem dispensar o suporte tecnológico), o único modo de dar sentido ao fluxo de informações que transita pelas redes. Elas notam, no entanto, que

falta ao comunicador da era digital se posicionar diante desse novo panorama curatorial explorando competências de re-mediação, agregação de audiências, mineração de dados, inteligência distribuída, agenciamentos e adição de valor às informações (CORRÊA e BERTOCCHI, 2013, p. 26).

Nesse sentido, é relevante sugerir a aproximação da curadoria como verificação com o jornalismo digital de quinta geração ${ }^{7}$, tal como definido por Barbosa, que enxerga "as mídias móveis como agentes propulsores de um novo ciclo de inovação” (BARBOSA, 2013, p. 34). Embora a pesquisadora pense sobre o papel das mídias móveis no jornalismo de uma maneira ampla, reconfigurando "a produção, a publicação, a distribuição, a circulação, a recirculação, o consumo e a recepção de conteúdos jornalísticos em multiplataformas" (BARBOSA, 2013, p. 42), suas reflexões podem ser interessantes para pensar os processos jornalísticos em um contexto de breaking news, quando a maioria das informações disponíveis são oriundas de dispositivos móveis.

Há de se convir que as habilidades necessárias para verificar fatos em uma cobertura de crise realizada remotamente diferem um

7 Para compor as quatro gerações anteriores, Barbosa utiliza as definições de Mielniczuk (2003) para a primeira, segunda e terceira (ampliando-a). A quarta foi desenvolvida pela própria pesquisadora (2007, 2008 e 2009). Optei por não reproduzir as definições de todas as gerações por considerar que, se for o caso de utilizá-las, isso pode ser feito mais adiante, de preferência já com um conhecimento maior das pesquisas citadas. Por ora, considero ser apropriado citá-las como parte da contribuição de Bertocchi. 
pouco daquelas consagradas na história do jornalismo - embora os cuidados com a precisão, como dissemos, devam permanecer. Ao mesmo tempo, podemos entender que essas habilidades - ainda incipientes na profissão - tendem a convergir com as competências apontadas por Corrêa e Bertocchi. Daí a necessidade de se debruçar sobre a curadoria em jornalismo, encarando-a seriamente.

Os jornalistas encarregados pela cobertura da operação norte-americana em Abbottabad percorreram um caminho até as informações disponibilizadas por Athar no Twitter. Para vencer este caminho, foi necessário dispor de determinadas técnicas e contar com certas habilidades para chegar até o depoimento, checá-lo e, por fim, utilizá-lo como parte da narrativa noticiosa, contextualizando-o. Um exemplo de como um comunicador pode usar o poder da rede para gerar conhecimento. Desde que, claro, esteja preparado e que conte com uma estrutura mínima para dar conta de tal tarefa no seu local de trabalho.

\section{A tecnologia e a afirmação do jornalismo}

Diante deste cenário, parece interessante apontar métodos confiáveis de edição em um contexto em que o gatewatching desponta como uma alternativa relevante, levantando discussões que tenham como objetivo afirmar tal prática dentro do jornalismo e chamando a atenção para o que está por vir. Assumir essa postura é o primeiro passo para que a curadoria de conteúdo adquira e cristalize elementos essenciais de um jornalismo de qualidade - apuração, contextualização, interpretação, sentido -, mesmo que o profissional à frente dessa tarefa tenha precisado abrir mão da "paternidade exclusiva da geração da notícia” (GUERRINI, 2013, p. 11).

Os casos de Athar na operação no Paquistão e do terremoto na Costa Rica são úteis para pensar sobre a construção da notícia nesse contexto e sublinham o potencial que possui o jornalista curador envolvido nessa atividade. Trata-se de um profissional capaz de gerar conhecimento ao saber se movimentar em meio às informações disponíveis na rede, encarando a apuração e a verificação como um processo de news gathering (coleta de notícias, em tradução livre) feita a distância e em tempo real pela internet. Aos poucos, reflexões a respeito desse tipo de prática começam a vir à tona na profissão. 
Como o raciocínio elaborado pelo jornalista Mark Little. Ele usa a expressão Human Algorithm ${ }^{8}$ (Algoritmo Humano) para falar das habilidades necessárias aos jornalistas para realizar uma curadoria de conteúdo na web. Essas habilidades são técnicas desenvolvidas a partir da transferência de características historicamente consideradas como qualidades de um bom repórter da "realidade física" para o ambiente virtual. Colocadas em prática com o auxílio de ferramentas digitais, elas se transformam em verdadeiros algoritmos humanos.

Nesse sentido, cabe destacar o pioneirismo do Verification Handbook ${ }^{9}$, ebook lançado em janeiro de 2014 que reúne as principais técnicas de verificação de conteúdo digital e em breaking news. Na introdução o livro, Craig Silverman e Rina Tsubaki, dois dos autores, chamam a atenção para o grande potencial existente na combinação entre a inteligência humana e os recentes avanços tecnológicos, mas pontuam que, sem desenvolver e treinar técnicas e processos, a tecnologia pode mais atrapalhar do que ajudar. Além disso, sublinham, ao entrevistar jornalistas de empresas como BBC e AP, que não é necessário ser um especialista em tecnologia para verificar conteúdo digital (SILVERMAN, 2014).

\section{Considerações finais}

Acreditamos que a cobertura jornalística de eventos urgentes em redes digitais é um recorte importante dos estudos de jornalismo, especialmente diante o desafio de afirmar o campo profissional e de pesquisa na sociedade em rede. A abordagem deste artigo introduz o tema, que tem potencial para ser tensionado de maneira mais profunda, explorando de maneira mais minuciosa os significados, para o jornalismo, de uma adaptação de processos de verificação ao ambiente digital e a incorporação de uma postura mais horizontal de um profissional consciente da necessidade das novas habilidades que precisa desenvolver.

Isso passa pela superação do temor em relação a um determinismo tecnológico ainda bastante frequente nas redações mais tradicionais e em jornalistas filiados a uma ideia clássica da profissão,

8 Ver mais em: http://blog.storyful.com/2011/05/20/the-human-algorithm-2/\#. UwNpR0JdUjE

${ }^{9}$ Ver mais em: http://verificationhandbook.com 
como também pela adequação das habilidades necessárias para um profissional responder às exigências impostas por este contexto, como disseram Corrêa e Bertocchi no trecho destacado. Ou seja, a familiarização de jornalistas com o ambiente digital, suas possibilidades e limitações. Não existem fórmulas, e as técnicas existentes evoluem junto com a tecnologia. Não se trata de nos debruçarmos sobre a especificidade dos métodos. Eles são muitos e têm naturezas diversas. A questão passa mais por fazer com que essas práticas, em seu conceito, sejam aceitas e incorporadas como verdadeiras práticas jornalísticas, e que o seu resultado seja considerado com tanto valor jornalístico quanto uma reportagem in loco.

\section{REFERENNCIAS}

ADGHIRNI, Zélia, Leal. Informação on-line: jornalista ou produtor de conteúdo? Anais do X Congresso Brasileiro de Ciências da Comunicação (Compós). Brasília, 2001.

ANDERSON, CW; BELL, Emily; SHIRKY, Clay. Jornalismo pósindustrial: adaptação aos novos tempos. Revista de Jornalismo ESPM edição brasileira da Columbia Journalism Review. Número 5, ano 2. Junho de 2013. Páginas 30 a 89.

\section{BARBOSA, Suzana. Jornalismo Digital em Base de Dados (JDBD) - Um} paradigma para produtos jornalísticos digitais dinâmicos. Tese de doutorado. Faculdade de Comunicação, Universidade Federal da Bahia, Salvador, 2007.

. Jornalismo convergente e continuum multimídia na quinta geração do jornalismo nas redes digitais. In: CANAVILHAS, João (org.). Notícias e Mobilidade, p. 33-54. Covilhã: Livros Labcom, 2013.

BERGER, Christa; TAVARES, Frederico M. B. Tipologias do acontecimento jornalístico. In: BENETTI, Marcia; FONSECA, Virginia Pradelina da Silveira (org.). Jornalismo e acontecimento: mapeamentos críticos. Florianópolis: Insular, 2010.

BRUNO, Nicola. Tweet first, verify later? How real-time information 
is changing the coverage of worldwide crisis events. Reuters Institute for the Study of Journalism: Londres, 2011. Disponível em: <https:// reutersinstitute.politics.ox.ac.uk/fileadmin/documents/Publications/ fellows_papers/2010-2011/TWEET_FIRST_VERIFY_LATER.pdf>. Acesso em: 10 nov. 2014.

BRUNS, Axel. Gatewatching: collaborative online news production. Nova York: Peter Lang, 2005.

CASTELLS, Manuel. A Era da Informação: Economia, Sociedade e Cultura. São Paulo: Paz e Terra, 1999.

CORRÊA, Elizabeth Nicolau Saad. Curadoria digital e o campo da comunicação. São Paulo: 2012. Disponível em: <http://issuu.com/ grupo-ecausp.com/docs/ebook_curadoria_digital_usp/1>. Acesso em: 18 jan. 2014.

GUERRINI, Federico. Newsroom curators \& independent storytellers: content curation as a new form of journalism. Reuters Institute for the Study of Journalism: Londres, 2013. Disponível em: <https:// reutersinstitute.politics.ox.ac.uk/sites/default/files/Newsroom $\% 20$ Curators $\% 20 \% 26 \% 20$ Independent $\% 2$ Storytellers $\% 20$ -Content\%20Curation $\% 20$ as $\% 20 a \% 20$ New\%20Form $\% 200 f \% 20$ Journalism.pdf>. Acesso em: 6 abr. 2016.

HEINRICH, Ansgard. Network Journalism: journalistic practice in interactive spheres. Nova York: Routlege, 2011.

HERMIDA, Alfred. Tweets and truth: journalism as a discipline of collaborative verification. In: Journalism Practice, Vol. 6, Issues 5-6. Routledge, 2012. Disponível em: <http://www.tandfonline.com/doi/ab s/10.1080/17512786.2012.667269\#.VwUTNRMrIo8>. Acesso em: 6 abr. 2016.

KHAZAN, Olga. What Should Reporters Learn in Journalism School? Disponível em: <http://www.theatlantic.com/education/ archive/2013/10/what-should-reporters-learn-in-journalismschool/280855/>. Acesso em: 18 jan. 2014. 
LITTLE, Mark. About Storyful: A letter from Mark Little, Founder/CEO. Disponível em: <http://storyful.com/about/>. Acesso em: 18 jan. 2014.

LITTLE, Mark. Human Algorithm. Disponível em: <http://blog. storyful.com/2011/05/20/the-human-algorithm-2/>. Acesso em: 6 abr. 2016.

LIU, Sophia B.. The Rise of Curated Crisis Content.

2010. Disponível em em: $<$ http://idl.iscram.org/show. php?record $=715 \&$ submit $=$ Cite $\&$ citeType $=P D F>$. Acesso em: 6 abr. 2016.

NOLAN, Markham. How to separate fact and fiction online. Londres, 2012. Disponível em: <https://www.youtube.com/ watch?v=sNV4yIyXXX0>. Acesso em: 6 abr. 2016.

PEREIRA, Fábio Henrique. O jornalista on-line: um novo status profissional? Uma análise sobre a produção da notícia na internet a partir da aplicação do conceito de 'jornalista sentado’. Dissertação de mestrado. Universidade de Brasília, Brasília, 2003.

. O 'Jornalista Sentado’ e a Produção da notícia on-line no CorreioWEb. Revista Em Questão, v. 10, n. 1, 2004. Disponível em $<$ http://seer.ufrgs.br/index.php/EmQuestao/article/view/85/45>. Acesso em: 6 abr. 2016.

SCHIAFFARINO, Júlia. Conceituações sobre o jornalismo internacional e a construção das esperas públicas internacionais. Anais do 10 Encontro de Nacional de Pesquisadores em Jornalismo (SBPJor), Pontifícia Universidade Católica do Paraná, Curitiba, 2012.

SHERIDAN, Gavin. Newsrooms as intelligence agencies. Disponível em: $<$ http://blog.storyful.com/2012/07/30/newsrooms-as-intelligenceagencies/\#.UvJobEJdUZ4>. Acesso em: 6 abr. 2016.

SILVERMAN, Craig. Verification Handbook. Disponível em: <http:// verificationhandbook.com/>. Acesso em: 18 jan. 2014. 
STANOEVSKA-SLABEVA, Katarina; SACCO, Vittoria; GIARDINA, Marco. Content Curation: a new form of gatewatching for social media? 2012. Disponível em <https://online.journalism.utexas.edu/2012/ papers/Katarina.pdf >. Acesso em: 6 abr. 2016.

TRAQUINA, Nelson. Teorias do jornalismo: porque as notícias são como são. Florianópolis: Insular, 2004.

Teorias do jornalismo: A tribo jornalística - uma comunidade interpretativa transnacional. Florianópolis: Insular, 2005.

WEINBERGER, D. Too Big to Know. Kindle Edtion, 2012. 
AÇÃO MIDIÁTICA, n.11. Jan/jun. 2016. Curitiba. PPGCOM-UFPR. ISSN 2238-0701

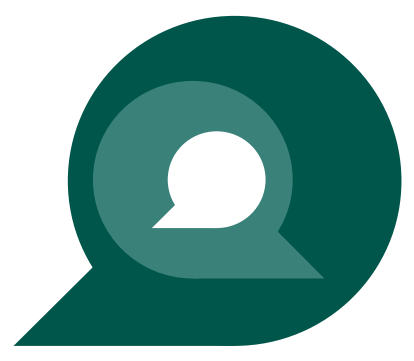

